Discussion Paper No. 05-87

\title{
Self-financing Tax/Subsidy \\ Mechanisms in Environmental \\ Regulation with Many Firms
}

Jörg Breitscheidel

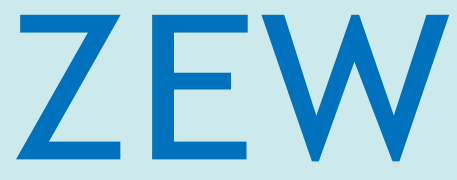

Zentrum für Europäische Wirtschaftsforschung $\mathrm{GmbH}$

Centre for European

Economic Research 
Discussion Paper No. 05-87

\title{
Self-financing Tax/Subsidy Mechanisms in Environmental Regulation with Many Firms
}

\author{
Jörg Breitscheidel
}

Download this ZEW Discussion Paper from our ftp server:

ftp://ftp.zew.de/pub/zew-docs/dp/dp0587.pdf

Die Discussion Papers dienen einer möglichst schnellen Verbreitung von neueren Forschungsarbeiten des ZEW. Die Beiträge liegen in alleiniger Verantwortung der Autoren und stellen nicht notwendigerweise die Meinung des ZEW dar.

Discussion Papers are intended to make results of ZEW research promptly available to other economists in order to encourage discussion and suggestions for revisions. The authors are solely responsible for the contents which do not necessarily represent the opinion of the ZEW. 


\section{Non-Technical Summary}

Self-financing tax/subsidy mechanisms can be a powerful policy tool to spur welfareenhancing investments in oligopolies. Consider environmental regulation settings where firms' investments in clean technologies are costly. Firms may behave strategically by refusing to invest, thus saving investment costs, and hoping to force the regulator to adopt looser regulation.

While the literature proposes self-financing regulatory mechanisms to solve hold-up problems in Cournot-duopolies, it is unclear whether these mechanisms work for an arbitrary number of firms as well. In a market with two firms the regulator can credibly trigger investments in emission reductions. If one firm invests and the other does not, the firm that does not comply must pay taxes, which are used in turn to subsidize the complying firm. This potentially creates a Prisoner's Dilemma for firms and equilibrium may exist in which all firms invest to avoid subsidizing others.

We analyze two different self-financing tax-subsidy mechanisms (announcing the tax rate versus announcing the subsidy rate) in a market with an arbitrary number of firms. The main results of the paper are as follows: Tax/subsidy mechanisms are applicable to a market with an arbitrary number of firms. Announcing the subsidy rate will solve the hold-up problem if the investment costs do not exceed the firm's net profit in the absence of regulation if there are at least three firms in the market. The investment incentive is even stronger than in a market with only two firms. Announcing the tax rate in a market with an arbitrary number of firms will also lead to investment by all firms in the subgame perfect equilibrium if marginal damage of emissions is large enough. 


\title{
Self-financing Tax/Subsidy Mechanisms in Environmental Regulation with Many Firms*
}

\author{
Jörg Breitscheidel ${ }^{\dagger}$
}

This Version: September 2005

\begin{abstract}
We consider the application of self-financing tax/subsidy mechanisms in environmental regulation and explore the question whether these mechanisms yield strong investment incentives in a market with many firms under Cournot competition. It turns out that the tax/subsidy mechanism with the announcement of the subsidy rate and the tax/subsidy mechanism with the announcement of the tax rate work for an arbitrary number of firms, which means that they yield strong incentives for investing in environmentally friendly technologies. The announcement of the subsidy rate is preferable for solving hold-up problems.
\end{abstract}

Keywords: Hold-up problems; Environmental regulation; Taxes and subsidies; Selffinancing mechanisms; Emission control

JEL classification: D43, D62, L50, Q28

\footnotetext{
${ }^{*}$ I thank Hans Gersbach for helpful ideas, comments and suggestions.

${ }^{\dagger}$ Centre for European Economic Research, Department of Environmental and Resource Economics, Environmental Management, L7.1, 68161 Mannheim, P.O. Box 103431, 68034 Mannheim, Germany, e-mail: joerg.breitscheidel@lycos.de
} 


\section{Introduction}

Self-financing tax/subsidy mechanisms can be a powerful policy tool to spur welfare-enhancing investments in oligopolies. Consider environmental regulation settings where firmsb4 investments in clean technologies are costly. Firms may behave strategically by refusing to invest, thus saving investment costs, and hoping to force the regulator to adopt looser regulation. Self-financing tax/subsidy mechanisms treat firms alike whether they invest or not. If, however one firm invests and the other does not, the firm that does not comply must pay taxes, which are used in turn to subsidize the complying firm. This potentially creates a Prisoner's Dilemma for firms and an equilibrium may exist in which all firms invest to avoid subsidizing others. The regulator can credibly trigger investments in emission reductions.

Hold-up problems are real-world phenomena. For instance, the standards specified by the 1970 American Clean Air Act were repeatedly delayed. Most dramatically, faced with industry claims that the proposed emission standards would shut down factories, Congress amended the Act in 1977, thus both weakening and postponing the standards. Similarly, in 1988 the government delayed standards for the 1989 model year. Further evidence of the hold-up problem can be found in Weimann (1995), who illustrates how the "cartel of silence" on the part of engineers prevents the government from imposing tighter regulations.

Another recent example illustrates credibility problems. In 1998, Congress included a provision in the highway bill that delayed for six to nine years the first steps towards bringing states into compliance with the Clean Air Act's long-standing goal of "reasonable progress" towards eliminating man-made haze in specially protected areas. Until Congress intervened, the Environmental Protection Agency had planned to ask states to file preliminary plans by 1999 showing how they would eventually raise visibility standards gradually over the next few decades by complying with the new rules that had been proposed two years before. ${ }^{1}$

While the literature proposes self-financing regulatory mechanisms to solve hold-up problems with two firms, it is unclear whether these mechanisms work for an arbitrary number of firms as well.

The paper is organized as follows: Section 2 gives an overview of the related literature and section 3 develops the basic model. Section 4 describes the tax/subsidy mechanism, while section 5 analyses different regulations. Section 6 concludes.

\section{Relation to the Literature}

Our paper relates to different strands of the literature.

Gersbach (2002) has suggested self-financing tax/subsidy mechanisms as a solution for hold-up problems by announcing subsidies when firms compete in a Cournot-Duopoly.

Additionally, our paper is related to the literature about the original hold-up problem, where a firm facing a single buyer may find investment unprofitable if, after making the

\footnotetext{
${ }^{1}$ See New York Times, May 27, 1998
} 
investment, the buyer offers to pay only marginal costs. This has been discussed in Klein, Crawford and Alchian (1978), Joskow (1987), Williamson (1983), and in the incompletecontract literature (see the survey by Hart (1995)).

The idea that threats or promises by the government may not be credible has been discussed in the literature on trade protection (Staiger and Tabellini (1987), Matsuyama (1990), Tornell (1991)), regulation of utilities (Salant and Woroch (1992)), Gilbert and Newbery (1994), Urbiztondo (1994)) and privatization (Levy and Spiller (1997)). The holdup problem is only solvable if there are means which make governmental regulation credible. In our paper we design a credible self-financing tax/subsidy scheme to spur investments by firms.

Our analysis also relates to mechanism design that uses the tools of multi-stage games and subgame perfect equilibria (see Varian (1994) or Moore (1992) for a review of the literature). From this perspective, our paper is an example of subgame perfect implementation of environmental regulation.

Finally, our paper draws on the work about the incentives to adopt clean technologies in the design of environmental policy instruments. Milliman and Prince (1989) and Jung, Krutilla and Boyd (1996) examine firms' incentives to invest in new technology and provide a ranking of different policy instruments (see also Laffont and Tirole (1996), Requate (1995) and Requate and Unold (2003)). In our context, we examine incentives to invest in clean technologies when a firm can influence the tightness of regulation by its investment decision.

\section{The Model}

We consider an industry with $n \geq 3$ firms, producing a homogenous good. The investment decisions of firms are denoted by $I_{i}, i=1, \ldots, n$ with

$$
I_{i}=\left\{\begin{array}{ll}
K & \text { if firm } i \text { invests } \\
0 & \text { if firm } i \text { does not invest }
\end{array} .\right.
$$

Similarly,

$$
a_{i}= \begin{cases}a & \text { if firm } i \text { has not invested } \\ 0 & \text { if firm } i \text { has invested }\end{cases}
$$

denote emissions per unit of output depending on the investment decisions of firms. Firms can reduce the emissions per unit of output from $a>0$ to zero by investing a fixed amount of $K$ in clean technologies.

$$
E=\sum_{i=1}^{n} a_{i} q_{i}
$$

is the resulting total amount of emissions, where $q_{i}$ denotes the output of firm $i$.

$$
Q=\sum_{i=1}^{n} q_{i}
$$


is the industry's output. Social welfare depends on consumer surplus $S(Q)$, on producer surplus net of investment costs $P(Q)$, on investment outlays $I_{1}+I_{2}$ and on the social costs of emissions $D(E) . D(E)$ is the social damage in terms of willingness to pay. Therefore, social welfare, denoted by $W$, is given by

$$
W=S(Q)+P(Q)-I_{1}-I_{2}-D(E) .
$$

We assume that the firms stand in Cournot competition and choose their production quantities $q_{i}, i=1, \ldots, n$. The inverse demand function is given by

$$
p(Q)=1-b Q,
$$

where $b$ is a positive constant. Marginal costs are assumed to be zero and independent of the installation of the abatement technology.

A number of comments are necessary here. First, our central assumption is that firms cannot be punished directly for not investing. It is impossible for the government to force firms to invest by penalizing non-investing firms financially or by closing them down. As discussed at length in the literature on incomplete contracts (see Hart (1995) for a survey), even when investments are observable, they are not verifiable in courts, and hence penalties directly dependent on investment behavior are not feasible. This is the case, for example, when investment in clean technologies is a by-product of other investments or when investment requires certain types of human capital for implementation. In the latter case firms can always claim that they are not able to generate the benefits from investment. A clear example of non-verifiable investments are R\&D efforts. Our model is applicable to R\&D where the success probability is high and, for convenience, is assumed in our case to be one. Second, we assume that the regulator does not pursue revenue objectives, in order to focus on solving hold-up problems. In turn, our self-financing constraint ensures that no funds from the government budget become involved. The tax/subsidy mechanism below could be adapted to include revenue objectives by considering the shadow costs of taxation in the economy. The scope for solving hold-up problems would, however, decrease.

\section{The Tax/Subsidy Mechanism}

We consider the following four-stage regulatory tax/subsidy mechanism:

- Stage 1: The government commits to use the following self-financing tax/subsidy scheme:

\begin{tabular}{|c|l|}
\hline (i) $\quad$ All firms pollute & Emissions tax $t^{0}$ \\
\hline $\begin{array}{c}\text { (ii) } m \text { firms are clean } \\
(1 \leq m \leq n-1)\end{array}$ & $\begin{array}{l}\text { Subsidy to the clean firm / firms, financed } \\
\text { by the taxation of the polluting firm / firms. } \\
(\text { tax/subsidy rule })\end{array}$ \\
\hline (iii) No firm pollutes & No taxes or subsidies \\
\hline
\end{tabular}


If all firms pollute, the regulator passes on the gains from taxation as a lump-sum transfer to the consumers. If $m(1 \leq m \leq n-1)$ firms are clean, the tax/subsidy rule is used. The regulator has two choices. He can set $s_{m}$, which denotes the subsidy per unit of product sold for the clean firms, or he can set $t_{m}$, which denotes the emissions tax per unit of output for the polluting firms. $s_{m}$ or $t_{m}$ are used if exactly $m$ firms have invested. The regulation of the two possible scenarios is as follows:

- The regulator sets the subsidy rate $s_{m}$ : He will adjust the taxation of the polluting firms such that the the self-financing condition is fulfilled. Since there is always an unique equilibrium in the product market, the regulator knows exactly whether the self-financing condition will be fulfilled. The regulator may not set the subsidy rate to such a high value value that the polluting firms could not pay the required taxes.

- The regulator sets the tax rate $t_{m}$ : The clean firms receive the gains from taxation as a lump-sum transfer. ${ }^{2}$

- Stage 2: Firms decide whether or not to invest in emissions reduction.

- Stage 3: The government uses the tax/subsidy scheme and sets $t^{0}$ and $s_{m}$ or $t_{m}$.

- Stage 4: Firms compete and produce. ${ }^{3}$

To simplify the exposition, we assume that a firm will choose the largest production quantity if different production quantities maximize the profit of the firm. Because the firms are identical, we consider only equilibria where the firms choose the same production quantities, depending on their investment decisions.

To ensure that the self-financing condition is fulfilled for every possible combination of production quantities and the subsidy rate if the regulator sets $s_{m}$, we supplement our tax/subsidy mechanism at stage 1 . If the regulator sets a too high subsidy rate $s_{m}$ (by accident) and/or one or more clean firms set a too high production quantity (by accident) and/or one or more polluting firms set a too low production quantity such that the self-financing condition cannot be fulfilled, then taxation occurs to the maximal level and subsidies are adjusted accordingly as well.

This rule controls for strategic considerations of players and for mistakes. The polluting firms have no incentive to deviate from their profit-maximizing production quantity, given the regulator implements $s_{m}$ and the equilibrium reactions of the other firms, if net profit of the polluting firms is nonnegative since deviating yields a net profit of zero.

\footnotetext{
${ }^{2}$ In this case, the self-financing condition is always fulfilled because the lump-sum subsidy is zero if there are no revenues from taxation.

${ }^{3}$ Each firm is allowed to exit.
} 
There are $n-1$ possible subsidy rates $s_{1}, \ldots, s_{n-1}$ and $n-1$ possible tax rates $t_{1}, \ldots, t_{n}$. The subsidy rate $s_{m}$ or the tax rate $t_{m}$ is used if exactly $m$ firms have invested. Note that, given the subsidy rate and the production quantity of the clean firms, the total tax burden of the polluting firms is of a lump-sum nature if the subsidy rate is announced.

\section{$5 \quad$ Different Regulations}

\subsection{No Regulation}

Without regulatory intervention, firms choose the following production quantities $q_{i}^{c}$ and make the following gross profits $\pi_{i}^{c}$ (product-market profits) in the unique Nash-equilibrium:

$$
\begin{aligned}
q_{i}^{c} & =\frac{1}{(n+1) b}, \quad i=1, \ldots, n, \\
\pi_{i}^{c} & =\frac{1}{(n+1)^{2} b}, \quad i=1, \ldots, n
\end{aligned}
$$

The investment outlays $K$ are assumed to be lower than $\pi_{1}^{c}$, such that investment by all firms is possible. It would be impossible to achieve investment by all firms at higher investment costs without violating the budget-constraint.

\subsection{Standard Emission Taxation}

Let us assume that the regulator imposes emissions taxes on the output. The tax rate is of the welfare-maximizing kind and depends on the number of firms polluting. The tax revenues are distributed lump-sum to the consumers. Since investing firms are clean and non-investing firms pollute, we treat "investing" and "clean" as well as "non-investing" and "polluting" as synonyms from now on.

Let us temporarily suppose that no firm has invested. The optimal tax rate is denoted by $t^{0}$ and can be zero or positive. The tax revenues are distributed to consumers as a lump-sum transfer. The gross profit of firm $i(i \in\{1, \ldots, n\})$ is denoted by $\pi_{i}^{0}$ and given by

$$
\pi_{i}^{0}=\left((1-b Q)-t^{0}\right) q_{i} .
$$

The firms choose the following quantities, denoted by $q_{i}^{0}$, in the unique equilibrium

$$
q_{i}^{0}=\frac{1-t^{0}}{3 b}
$$

whereby $t^{0} \in[0,1] . q_{i}^{0}$ is zero for $t^{0}=1$. The profits are given by

$$
\pi_{i}^{0}=\frac{\left(1-t^{0}\right)^{2}}{9 b}
$$


The regulator has to choose $t^{0} \in[0,1]$ to maximize social welfare which is given by

$$
W=\frac{b}{2}\left(n q_{1}^{0}\right)^{2}+n t^{0} q_{1}^{0}+n \pi_{1}^{0}-D\left(n a q_{1}^{0}\right) .
$$

\subsection{The Tax/Subsidy Mechanism with the Announcement of the Subsidy Rate}

In this subsection we assume that the standard emission taxation does not yield the investment by all firms but that investment by all firms is desired from a welfare point of view, even if the non-investing firms are taxed optimally. Now we are in a situation where investment by all firms is socially desirable but not all firms will invest if the regulator uses the standard emission taxation, although the firms are able to finance the investment outlays by their own profits. This situation is denoted by "hold-up problem".

To assure that our calculated subsidy rates are always credible we make the following assumption: Given $m \in[1, n-1]$ firms have invested; $D$ is of such a functional form that $W$ is an increasing function of $s_{m}$ if $E$ is an increasing function $s_{m}$ as well.

The intuition is the following. The increase in $s_{m}$ yields a decrease of $E$ and $-\frac{\partial D(E)}{\partial E}$ is assumed to be "large enough", wherefore a possible decrease of $P+S$ is at least compensated. Our assumption is automatically fulfilled if $S+P$ is increasing in $s_{m}$, which holds in many cases. In such cases the assumption above is always fulfilled.

In the following we consider the equilibrium-situation. An equilibrium is completely characterized by the tax rate $t^{0}$, the subsidy rates $s_{1}, \ldots, s_{n-1}$, the investment decisions $I_{1}, \ldots, I_{n}$ and the production quantities $q_{1}, \ldots, q_{n}$. The particular tax rate $t$ is determined by the self-financing condition.

If all firms invest, then the regulator will introduce no regulation. In this case the firms will choose the production quantities $q_{i}^{c}$ and make the net profits $\pi_{i}=\pi_{i}^{c}-K$.

If no firm invests, then the regulator will use the standard emission taxation. In this case the firms will choose the production quantities $q_{i}^{0}$ an make the net profits $\pi_{i}=\pi_{i}^{0}$.

No we consider the situation where (without the loss of generality) the first $m$ firms invest $(1 \leq m \leq n-1)$. The production quantity which causes no emissions is denoted by $Q_{I}=\sum_{i=1}^{m} q_{i} . Q_{N I}=\sum_{i=m+1}^{n} q_{i}$ denotes the production quantity which causes emissions. The tax rate $t$ is determined by the self-financing condition:

$$
t=s_{m} \frac{Q_{I}}{Q_{N I}}
$$

The first firmb4s profit (and the profit of every other firm investing) is

$$
\pi_{1}=\left(1-b Q+s_{m}\right) q_{1}-K=\left(1-b\left(q_{1}+Q_{-1}\right)+s_{m}\right) q_{1}-K
$$

From the first order condition of the first firmb4s profit maximization problem follows

$$
q_{1}=\frac{1-b q_{n}(n-m)+s_{m}}{b(1+m)} .
$$


The second order condition of a maximum is fulfilled. The $n$-th firm (and every other non-investing firm) earns the profit

$$
\pi_{n}=\left(1-b Q-s_{m} \frac{Q_{I}}{Q_{N I}}\right) q_{n}=\left(1-b\left(q_{n}+Q_{-n}\right)-s_{m} \frac{Q_{I}}{\frac{n-m-1}{n-m} Q_{N I}+q_{n}}\right) q_{n},
$$

with $Q_{-n}=Q-q_{n}$. The following first order condition of the firm $n$ arises (again, the second order condition of a maximum is fulfilled.):

$$
\begin{aligned}
& 0=1-b\left(Q_{-n}+2 q_{n}\right)-\frac{(m-n)(1+m-n) Q_{I} Q_{N I} s_{m}}{\left(Q_{N I}+(m-n)\left(q_{n}+Q_{N I}\right)\right)^{2}} \\
& \Longleftrightarrow 0=1-b\left(m q_{1}+(n-m+1) q_{n}\right)-\frac{(m-n)(1+m-n) m q_{1}(n-m) q_{n} s_{m}}{\left(q_{n}((n-m)+(m-n)(1+(n-m)))^{2}\right.}
\end{aligned}
$$

(15) inserted in (17) yields

$$
Q_{N I}=\frac{\sqrt{4 m(1+m-n)(1+n) s_{m}\left(1+s_{m}\right)+\left(n-m\left(1+s_{m}\right)\right)^{2}}+n-m\left(1+s_{m}\right)}{2 b(1+n)}
$$

since $Q_{N I}=(n-m) q_{m}$. Therefore the production quantity which causes no emissions amounts to

$$
Q_{I}=\frac{m}{b(1+m)}\left(1+s_{m}-\frac{\sqrt{4 m(1+m-n)(1+n) s_{m}\left(1+s_{m}\right)+\left(n-m\left(1+s_{m}\right)\right)^{2}}+n-m\left(1+s_{m}\right)}{2(1+n)}\right) .
$$

We choose $s_{m}$ such that the $n$-th firm makes a profit of zero in the equilibrium since it has not invested: ${ }^{4}$

$$
\pi_{n}=\left(1-b\left(Q_{I}+Q_{N I}\right)-s_{m} \frac{Q_{I}}{Q_{N I}}\right) \frac{Q_{N I}}{n-m}=0
$$

We find the following subsidy rate, denoted by $s_{m}^{*}$, as the solution of the problem:

$$
s_{m}^{*}=\frac{1}{2}\left(\frac{2+m}{\sqrt{m} \sqrt{4+m}}-1\right) .
$$

The subsidy rate $s_{m}^{*}$ only depends on the number of firms investing $m$ and not on the number of firms in the market, $n$. The subsidy rate is a decreasing function of $m$ :

$$
\frac{\partial s_{m}^{*}}{\partial m}=-\frac{2}{(m(4+m))^{\frac{3}{2}}}<0
$$

No we are in a position to calculate the net profit of a firm investing (for example the first firmb4s profit), denoted by $\pi_{1}(m, n)$. It depends on $m$ and $n$ :

$$
\begin{aligned}
& \pi_{1}(m, n)=\left(1-b\left(Q_{I}+Q_{N I}\right)+s_{m}\right) \frac{Q_{I}}{m}-K \\
& \quad=\frac{\left\{(2+m)(2+m+\sqrt{m} \sqrt{4+m}+2 n)-\sqrt{2} \sqrt{m} \sqrt{4+m} \sqrt{(2+m) \sqrt{\frac{m}{4+m}}(m-2 n)+\frac{8+m\left(10+m[4+m]-2 m n+2 n^{2}\right)}{4+m}}\right\}^{2}}{16 b m(1+m)^{2}(4+m)(1+n)^{2}}-K
\end{aligned}
$$

\footnotetext{
${ }^{4}$ This maximizes $W$ by assumption.
} 
Note that it is of no advantage for a non-investing firm to choose a production quantity which lies below $\frac{Q_{N I}}{n-m}$. By assumption, this firm will be taxed such that it makes a profit of zero. This firm doesn't benefit from that kind of behavior and therefore a non-investing firm produces the quantity $\frac{Q_{N I}}{n-m}$.

The following proposition contains our main results:

Proposition 1 There are $n-1$ subsidy rates $s_{1}^{*}, \ldots, s_{n-1}^{*}$ such that $\left(t^{0}, s_{1}^{*}, \ldots, s_{n-1}^{*}, I_{1}=\ldots=\right.$ $\left.I_{n}=K, q_{1}=\ldots=q_{n}=\frac{1}{(n+1) b}\right)$ is the unique subgame perfect equilibrium. All firms invest and no regulation is introduced.

The proof of proposition 1 is given in the appendix. The intuition is the following: The regulator maximizes social welfare by choosing the particular subsidy rate. Besides, it is a strictly dominant strategy for the firms, to invest.

In the analysis with two firms, one supplementary assumption is needed to ensure that all firms invest in the subgame perfect equilibrium. This assumption is $K<1,8 \pi_{1}^{c}-\pi_{1}^{0}$. In a market with more than two firms this assumption is not needed since the investment incentives are stronger if there are more firms in the market, given all other firms have not invested.

\subsection{Tax/Subsidy Mechanism with the Announcement of the Tax Rate}

In this subsection we do not assume that the standard emission taxation does not yield the investment of all firms in the unique subgame perfect equilibrium. The reason is the following: As Breitscheidel and Gersbach (2002) worked out, the latter assumption implies that $D$ is such that the marginal damage of emissions is below a certain value, leading to the consequence that the regulator has to announce a tax rate that does not lead to zero profit for the non-investing firms in the subgame perfect equilibrium. Because of that it is not certain that all firms will invest in the equilibrium. In this subsection we analyze a situation where the marginal damage of emissions has no upper bound while not assuming that the standard emission taxation does not yield investment by all firms. Note: In this subsection we leave the focus of the hold-up problem from subsection 5.3.

We assume that $D$ is of such a functional form that $W$ is increasing in $t_{m}$ (until the profit of a non-investing firm, which is decreasing in $t_{m}$, becomes zero). The intuition here is the following. An increase of $t_{m}$ yields a decrease of $E$, and $D(E)$ is assumed to be "large enough", such that a possible decrease of $P(Q)+S(Q)$ is at least compensated.

Now we consider equilibrium situations. An equilibrium is completely characterized by the tax rate $t^{0}$, the tax rates $t_{1}, \ldots, t_{n-1}$, the investment decisions $I_{1}, \ldots, I_{n}$ and the production quantities $q_{1}, \ldots, q_{n}$. The particular subsidy rate $s$ is determined by the self-financing condition. 
As in the case with the announcement of the subsidy rate, the firms make the profit $\pi_{i}=\pi_{i}^{c}-K\left(\pi_{i}=\pi_{i}^{0}\right)$ and produce the quantities $q_{i}^{c}\left(q_{i}=q_{i}^{0}\right)$ if all firms invest (no firm invests).

Suppose without the loss of generality that the first $m(1 \leq m \leq n-1)$ firms have invested. Again we use the notation $Q_{I}=\sum_{i=1}^{m} q_{i}$ and $Q_{N I}=\sum_{i=m+1}^{n} q_{i}$. As mentioned above, the subsidy rate $s$ is determined by the self-financing condition:

$$
s=t_{m} \frac{Q_{N I}}{Q_{I}}
$$

The first firmb4s profit (and the profit of every other firm investing) amounts to

$$
\pi_{1}=\left(1-b Q+t_{m} \frac{Q_{N I}}{Q_{I}}\right) q_{1}-K .
$$

The first order condition of profit maximization is

$$
\frac{\partial \pi_{1}}{\partial q_{1}}=1-b\left(q_{1}+Q\right)+\frac{Q_{N I}\left(Q_{I}-q_{1}\right) t_{m}}{Q_{I}^{2}}=0 .
$$

The second order condition is fulfilled and the profit of the $n$-th firm (and every other non-investing firm) amounts to

$$
\pi_{n}=\left(1-b Q-t_{m}\right) q_{n}
$$

The first and second order conditions of profit maximization are

$$
\begin{gathered}
\frac{\partial \pi_{n}}{\partial q_{n}}=1-b\left(q_{n}+Q\right)-t_{m}=0 \\
\frac{\partial^{2} \pi_{n}}{\partial\left(q_{n}\right)^{2}}=-2 b<0
\end{gathered}
$$

From equations (26) and (28) (and $\left.m q_{1}=Q_{I},(n-m) q_{n}=Q_{N I}\right)$ follow the production quantities depending on the tax rate:

$$
\begin{aligned}
& q_{1}=\frac{m+t_{m}(n-m)+\sqrt{4(m-1)(m-n)(1+n)\left(t_{m}-1\right) t_{m}+\left(m\left(t_{m}-1\right)-n t_{m}\right)^{2}}}{2 b m(1+n)} \\
& q_{n}=\frac{-2(n+1)+t_{m}(2-m+3 n)+m+\sqrt{4(m-1)(m-n)(1+n)\left(t_{m}-1\right) t_{m}+\left(m\left(t_{m}-1\right)-n t_{m}\right)^{2}}}{2 b(m-n-1)(1+n)}
\end{aligned}
$$

We choose the tax rate such that the $n$-th firmb4s profit becomes zero. ${ }^{5}$ This tax rate is denoted by $t_{m}^{*}$ and given by

$$
t_{m}^{*}=\frac{1}{1+m} .
$$

\footnotetext{
${ }^{5}$ This maximizes $W$ in the given framework.
} 
As in the case of the announcement of the subsidy rate, the tax rate depends only on $m$ and not on $n$. The production quantities and the profit of an investing firm are

$$
q_{1}=\frac{1}{b(1+m)}, \quad q_{n}=0, \quad \pi_{1}=\frac{1}{b(1+m)^{2}}-K .
$$

The subsidy rate is zero since $q_{n}=0$. In the appendix we show:

Proposition 2 There are $n-1$ tax rates $t_{m}^{*}=\frac{1}{1+m}$ such that $\left(t^{0}, t_{1}^{*}, \ldots, t_{n-1}^{*}, I_{1}=\ldots=I_{n}=\right.$ $\left.K, q_{1}=\ldots=q_{n}=\frac{1}{(n+1) b}\right)$ is the unique subgame perfect equilibrium. All firms invest and no taxes or subsidies are introduced.

\section{Conclusions}

Our main results are the following: The tax/subsidy mechanism is applicable to a market with an arbitrary number of firms.

Announcing the subsidy rate will solve the hold-up problem if the investment costs do not exceed the firmb4s net profit in the absence of regulation if there are at least three firms in the market. The investment incentive is in a certain sense stronger than in a market with only two firms since the investment costs do not have to be smaller than $1,8 \pi_{1}^{c}-\pi_{1}^{0}$ to reach an investment of all firms in the unique subgame perfect equilibrium.

Announcing the tax rate in a market with an arbitrary number of firms will also lead to investment by all firms in the subgame perfect equilibrium if marginal damage of emissions is large enough. There are no fundamental differences in comparison to the two-firm case.

\section{Appendix}

\subsection{Proof of Proposition 1}

\section{Stage 4}

The firms behave rationally since they maximize profits by choosing their production quantities as described in subsection 5.3.

Stage 3

1. All firms have invested:

The regulator introduces no regulation; there are no emissions.

2. One firm has invested:

The regulator maximizes social welfare by choosing the tax rate $t^{0}$. 
3. $m$ firms have invested $(1 \leq m \leq n-1)$ :

Suppose without the loss of generality that the first $m$ firms have invested.

First we will calculate an upper bound of the subsidy rate $s_{m}^{*}$. Then we will show that the profit of a non-investing firm and $Q_{N I}$ are decreasing functions of $s_{m}$ in the relevant range $\left(0 \leq s_{m} \leq s_{m}^{*}=\frac{1}{2}\left(\frac{2+m}{\sqrt{m} \sqrt{4+m}}-1\right)\right)$ by using this upper bound.

Social welfare increases by assumption if $Q_{N I}$ decreases (if the regulator uses the tax/subsidy mechanism with the announcement of the subsidy rate). Therefore the regulator increases social welfare by raising the subsidy rate from 0 to $s_{m}^{*}$. The regulator is not allowed to implement a higher subsidy rate than $s_{m}^{*}$ since the self-financing condition could not be fulfilled else. Thatb4s why the subsidy rate $s_{m}^{*}$ maximizes social welfare.

(a) We consider the function $m * s_{m}^{*}$. The first order condition of a maximum is

$$
\frac{\partial\left(m * s_{m}^{*}\right)}{\partial m}=\frac{1}{2}\left(\frac{4+m(6+m)}{\sqrt{m}(4+m)^{\frac{3}{2}}}-1\right)=0 .
$$

This results in

$$
m=2(\sqrt{2}-1) .
$$

The second order condition is fulfilled:

$$
\left.\frac{\partial\left(m * s_{m}^{*}\right)}{\partial m}\right|_{m=2(\sqrt{2}-1)}=\left.\frac{2(m-2)}{m^{\frac{3}{2}}(4+m)^{\frac{5}{2}}}\right|_{m=2(\sqrt{2}-1)}=1-\frac{3}{2 \sqrt{2}}<0
$$

The considered function reaches its maximal value at $m=2(\sqrt{2}-1)$. This implies the following bounds of $s_{m}^{*}$ :

$$
\begin{gathered}
0 \leq m s_{m}^{*} \leq\left.\left(m s_{m}^{*}\right)\right|_{m=2(\sqrt{2}-1)}=3-2 \sqrt{2} \\
\Longrightarrow 0 \leq s_{m}^{*} \leq \frac{3-2 \sqrt{2}}{m}
\end{gathered}
$$

From $3-2 \sqrt{2}<\frac{1}{5}$ follows

$$
0 \leq s_{m}^{*} \leq \frac{1}{5 m} .
$$

(b) We still have to show that the profit of a non-investing firm is a decreasing function of the subsidy rate $s_{m} \in\left[0, s_{m}^{*}\right]$. The profit of a non-investing firm is given by

$$
\begin{aligned}
\pi_{n}= & \left(1-b Q-s_{m} \frac{Q_{I}}{Q_{N I}}\right) \frac{Q_{N I}}{n-m} \\
= & \frac{n-m\left(1+s_{m}\right)\left(1+m-n+(4+3 m+2(2+m) n) s_{m}\right)}{2 b(1+m)(n-m)(1+n)^{2}} \\
& +\frac{\left(1+m+m s_{m}\right) \sqrt{4 m(1+m-n)(1+n) s_{m}\left(1+s_{m}\right)+\left(n-m\left(1+s_{m}\right)\right)^{2}}}{2 b(1+m)(n-m)(1+n)^{2}} .
\end{aligned}
$$


We have

$$
\begin{aligned}
\frac{\partial \pi_{n}}{\partial s_{m}} & <0 \\
& \Longleftrightarrow \frac{\partial}{\partial s_{m}} \pi_{n} 2 b(1+m)(n-m)(1+n)^{2}<0 \\
& \Longleftrightarrow \lambda+\mu+\nu<0,
\end{aligned}
$$

where $\lambda, \mu$ and $\nu$ are defined as follows:

$\begin{aligned} \lambda & \equiv\left(-1-m+n-(4+3 m+2(2+m) n) s_{m}-(4+3 m+2(2+m) n)\left(1+s_{m}\right),\right. \\ \mu & \equiv \sqrt{4 m(1+m-n)(1+n) s_{m}\left(1+s_{m}\right)+\left(n-m\left(1+s_{m}\right)\right)^{2}}, \\ \nu & \equiv \frac{\left(1+m+m s_{m}\right)\left(2+4 s_{m}-n\left(1+n\left(2+4 s_{m}\right)\right)+m\left(3+5 s_{m}+n\left(2+4 s_{m}\right)\right)\right)}{\sqrt{4 m(1+m-n)(1+n) s_{m}\left(1+s_{m}\right)+\left(n-m\left(1+s_{m}\right)\right)^{2}}}\end{aligned}$

$\lambda$ has a maximum at $s_{m}=0$ :

$$
\begin{gathered}
\frac{\partial \lambda}{\partial s_{m}}=-2(4+3 m+2(2+m) n)<0, \\
\left.\lambda\right|_{s_{m}=0}=-5-3 n-2 m(2+n)
\end{gathered}
$$

$\mu$ has a maximum at $s_{m}=0$ as well since we have $4 m(1+m-n)(1+n)<0$ and $n>m(1+s)$ (because of $\left.s_{m} \leq \frac{1}{5 m}\right)$ :

$$
\left.\mu\right|_{s_{m}=0}=n-m
$$

Therefore we have

$$
\lambda+\mu \leq\left.\lambda\right|_{s_{m}=0}+\left.\mu\right|_{s_{m}=0}=-(1+m)(5+2 n)<0 .
$$

The correctness of $\frac{\partial \pi_{n}}{\partial s_{m}}<0$ is proven if $\nu \leq 0$ holds. $\nu>0$ implies

$$
m \geq \underbrace{\frac{-2+n-4 s_{m}+n^{2}\left(2+4 s_{m}\right)}{3+2 n+5 s_{m}+4 n s_{m}}}_{\xi} .
$$

$\xi$ is an decreasing function of $s_{m}$ an has a lower bond at $s_{m}=\frac{1}{5}\left(\geq \frac{1}{5 m}\right)$ :

$$
\frac{\partial \xi}{\partial s_{m}}=-\frac{(2+n)(1+2 n)}{(3+5 s+n(2+4 s))^{2}}<0
$$

$\nu>0$ implies

$$
m \geq\left.\xi\right|_{s_{m}=\frac{1}{5}}=n-\frac{14+15 n}{20+14 n}>n-2
$$

and therefore

$$
m=n-1 .
$$

That is why $\nu>0$ can only hold with $m=n-1$. We consider the following two cases: 
i. $m<n-1$ : We have

$$
\nu \leq 0
$$

and therefore

$$
\lambda+\mu+\nu<0
$$

ii. $m=n-1$ :

$$
\nu=n+(n-1) s_{m}
$$

is an increasing function of $s_{m}$ and has an upper bound at $s_{m}=\frac{1}{5 m}=\frac{1}{5(n-1)}$. We have

$$
\nu \leq n+\frac{1}{5}
$$

and

$$
\lambda+\mu+\nu \leq-n(5+2 n)+n+\frac{1}{5}=-n(4+2 n)+\frac{1}{5}<0 .
$$

For that reason we have

$$
\frac{\partial \pi_{n}}{\partial s_{m}}<0 \quad \forall 1 \leq m, m+1 \leq n .
$$

Note: Inequality (34) has not to be fulfilled for $n=2$. But it is no problem that the inequality holds for $n=2$.

(c) We still have to show that $\frac{\partial Q_{N I}}{\partial s_{m}}<0$ holds. $Q_{N I}$ is described by the following function:

$$
Q_{N I}=\frac{\sqrt{4 m(1+m-n)(1+n) s_{m}\left(1+s_{m}\right)+\left(n-m\left(1+s_{m}\right)\right)^{2}}+n-m\left(1+s_{m}\right)}{2 b(1+n)}
$$

$Q_{N I}$ is a strictly decreasing function of $s_{m}$ :

$$
\begin{aligned}
& \frac{\partial Q_{N I}}{\partial s_{m}}<0 \\
& \Longleftrightarrow \frac{\partial\left(-m s_{m}+\sqrt{4 m(1+m-n)(1+n) s_{m}\left(1+s_{m}\right)+\left(n-m\left(1+s_{m}\right)\right)^{2}}\right)}{\partial s_{m}}<0 \\
& \quad \Longleftrightarrow m\left(-1+\frac{2+4 s_{m}-n\left(1+n\left(2+4 s_{m}\right)\right)+m\left(3+5 s_{m}+n\left(2+4 s_{m}\right)\right)}{\sqrt{4 m(1+m-n)(1+n) s_{m}\left(1+s_{m}\right)+\left(n-m\left(1+s_{m}\right)\right)^{2}}}\right)<0 \\
& \quad \Longleftrightarrow 2+4 s_{m}-n\left(1+n\left(2+4 s_{m}\right)\right)+m\left(3+5 s_{m}+n\left(2+4 s_{m}\right)\right) \\
& \quad \equiv f\left(m, n, s_{m}\right)<0
\end{aligned}
$$

We make a case differentiation: 
i. $n=m+1$ :

$$
\begin{aligned}
& f\left(m, n=m+1, s_{m}\right)=m s_{m}-1, \\
& \frac{\partial f\left(m, n=m+1, s_{m}\right)}{\partial s_{m}}=m>0
\end{aligned}
$$

To calculate an upper bound we set $s_{m}=\frac{1}{5 m}$ :

$$
\begin{aligned}
f(m, n & \left.=m+1, s_{m}=\frac{1}{5 m}\right)=-\frac{4}{5}<0 \\
& \Longrightarrow \frac{\partial Q_{N I}}{\partial s_{m}}<0 \quad \text { if } n=m+1
\end{aligned}
$$

ii. $n \geq m+2$ :

$$
\begin{aligned}
\frac{\partial f\left(m, n, s_{m}\right)}{\partial s_{m}} & =4-4 n^{2}+m(5+4 n)=4+5 m+4 n(m-n) \\
& \leq 4+5 m-8 n \leq 4+5 m-16-8 m=-12-3 m<0
\end{aligned}
$$

To calculate an upper bound we can set $s_{m}=0$ :

$$
f\left(m, n, s_{m}=0\right)=2-n(1+2 n)+m(3+2 n) \leq-2(2+n)<0
$$

To sum up, we have:

$$
\frac{\partial Q_{N I}}{\partial s_{m}}<0 \quad \forall n
$$

\section{Stage 2}

The correctness of the proposition is shown if it is a strictly dominant strategy to invest. We consider without the loss of generality the first firmb4s decision. It is a strictly dominant strategy to invest for the first firm if the following three conditions are fulfilled:

1. No other firm invests:

$$
\pi_{1}(1, n)>\pi_{1}^{0} \quad \forall n \geq 3
$$

If the first firm does not invest as well, all firms will be taxed with the tax rate $t^{0}$ and the first firm will make the profit $\pi_{1}^{0}$. In case of investment, the first firm is the only investing firm and its profit amounts to $\pi_{1}(1, n)$.

2. Some of the other firms invest:

$$
\pi_{1}(m, n)>0 \quad \forall 2 \leq m \leq n-1, n \geq 3
$$

The first firm makes a profit of zero if it does not invest and a profit of $\pi_{1}(m, n)$ if it invests. 
3. Every other firm invests:

$$
\pi_{1}^{c}-K>0
$$

The first firmb4s profit amounts to $\pi_{1}^{c}$ (zero) if it invests (does not invest).

The inequality (37) is fulfilled by assumption. We still have to show the correctness of the inequalities (35) and (36).

1. First we consider inequality (35):

$$
\begin{aligned}
\pi_{1}(1, n) & =\frac{\left(\sqrt{(1+3 \sqrt{5}-2 n)^{2}}-3(3+\sqrt{5}+2 n)\right)^{2}}{320 b(1+n)^{2}}-K \equiv \Pi_{1}(1, n)-K>\pi_{1}^{0} \\
& \Longleftrightarrow \Pi_{1}(1, n)>2 \pi_{1}^{c} \quad\left(\text { since } K<\pi_{1}^{c} \text { and } \pi_{1}^{0} \leq \pi_{1}^{c}\right) \\
& \Longleftrightarrow\left(\sqrt{(1+3 \sqrt{5}-2 n)^{2}}-3(3+\sqrt{5}+2 n)\right)^{2} \equiv h(n)>640
\end{aligned}
$$

We make the following case differentiation:

(a) $n=3$ :

$$
h(3)=1024>640
$$

(b) $n \geq 4$ :

$$
\begin{aligned}
h(n) & =4(2 n+5+3 \sqrt{5})^{2}, \\
\frac{\partial h(n)}{\partial n} & =16(2 n+5+3 \sqrt{5})>0, \\
h(n & =4)=4(13+3 \sqrt{5})^{2}>640
\end{aligned}
$$

The inequality (35) is fulfilled.

2. Now we consider inequality (36):

$$
\begin{aligned}
\pi_{1}(m, n) & \equiv \Pi_{1}(n, m)-K>0 \\
& \Longleftrightarrow \Pi_{1}(n, m)-\pi_{1}^{c}>0 \\
& \Longleftrightarrow\left(\Pi_{1}(n, m)-\pi_{1}^{c}\right) b(n+1)^{2}>0
\end{aligned}
$$

$$
\begin{aligned}
& \Longleftrightarrow \\
& \frac{\left\{(2+m)(2+m+\sqrt{m} \sqrt{4+m}+2 n)-\sqrt{2} \sqrt{m} \sqrt{4+m} \sqrt{(2+m) \sqrt{\frac{m}{4+m}}(m-2 n)+\frac{8+m\left(10+m[4+m]-2 m n+2 n^{2}\right)}{4+m}}\right\}^{2}}{16 m(1+m)^{2}(4+m)}-1 \\
& \equiv i(m, n)>0
\end{aligned}
$$


Our procedure can be divided into two steps. We will modify the problem with two variables $(m, n)$ to a problem with only one variable $(m)$ in the first step. In the second step we will solve the problem with one variable.

(a) Step 1: We will show that $i(m, n)$ is an increasing function of $n$. We have

$$
\frac{\partial i(m, n)}{\partial n}>0 \Longleftrightarrow \frac{\partial y(m, n)}{\partial n}>0
$$

where

$$
\begin{gathered}
y(m, n) \equiv(i(m, n)+1) * 16 m(1+m)^{2}(4+m) . \\
\frac{\partial y(m, n)}{\partial n}=2 \delta(m, n) \gamma(m, n)
\end{gathered}
$$

follows, with

$$
\delta(m, n) \equiv 2(2+m)+\frac{\sqrt{2} m(\overbrace{8+m(6+m)+\sqrt{m} \sqrt{4+m}(m-2 n)})}{(4+m) \sqrt{(2+m) \sqrt{\frac{m}{4+m}}(m-2 n)+\frac{8+m\left(10+m[4+m]-2 m n+2 n^{2}\right)}{4+m}}}
$$

and

$$
\begin{aligned}
& \gamma(m, n) \equiv(2+m)(2+m+\sqrt{m} \sqrt{4+m}+2 n) \\
& \quad-\sqrt{2} \sqrt{m} \sqrt{4+m} \sqrt{(2+m) \sqrt{\frac{m}{4+m}}(m-2 n)+\frac{8+m\left(10+m[4+m]-2 m n+2 n^{2}\right)}{4+m}} .
\end{aligned}
$$

It is left to show that $\delta(m, n)$ and $\gamma(m, n)$ are positive for all $2 \leq m \leq n-1,3 \leq n$. First we consider $\delta(m, n)$ and afterwards $\gamma(m, n)$.

i. Consideration of $\delta(m, n)$ :

$$
\frac{\partial \delta(m, n)}{\partial n}=0 \quad \forall m+1 \leq n, n \neq n \tilde{\delta}(m, n)
$$

has a saltus at

$$
\tilde{n}=\frac{1}{2}\left(m+\frac{2+m}{\sqrt{\frac{m}{4+m}}}\right)
$$

and is continuous in $n$ else. That is why $\delta(m, n)$ can adopt three values, given $m$; one for all $n<n^{\tilde{n}}$, one for $n=n^{\tilde{r}}$ and one for all $n>n \tilde{n}$. We consider the three possible cases in turn:

A. $n<n^{\tilde{*}}$ :

$$
\phi(m, n)>0 \Longrightarrow \delta(m, n)>0
$$

B. $n=n^{\sim}$ :

$$
\delta(m, n)=2(2+m)>0
$$


C. $n>n^{\sim}$ : We choose $n=2 n^{\sim}$ since $\delta(m, n)$ is independent of $n$ for all $n>n$.

$$
\delta(m, n=2 n \tilde{)})=2(2+m)-\frac{\sqrt{2} m(8+m(6+m+\sqrt{m} \sqrt{4+m}))}{(4+m) \sqrt{\frac{8+m(10+\sqrt{m}(2+m) \sqrt{4+m}+m(4+m))}{4+m}}}
$$

is continuous in $m$ for $m>0$. Additionally, $\delta\left(m, n=2 n^{\sim}\right)$ is independent of $m$, which is shown below. From

$$
\frac{\partial^{2} \delta\left(m, n=2 n^{\tilde{n}}\right)}{\partial m^{2}}=0
$$

and the continuity of

$$
\begin{aligned}
& \frac{\partial \delta\left(m, n=2 n^{\sim}\right)}{\partial m} \\
& =\frac{4(4+m(5+3 m))+\sqrt{2}(\overbrace{m^{\frac{2}{3}} \sqrt{4+m}-(2+m)(4+m)}^{<0}) \sqrt{\frac{8+m(10+\sqrt{m}(2+m) \sqrt{4+m}+m(4+m))}{4+m}}}{2(4+m(5+2 m))}
\end{aligned}
$$

in $m \forall m \geq 1$ follows

$$
\frac{\partial \delta\left(m, n=2 n^{\tilde{}}\right)}{\partial m}=\frac{\partial \delta\left(m=2, n=2 n^{\sim}\right)}{\partial m}=0 \quad \forall m \geq 1 .
$$

That is why

$$
\delta(m, n)=\delta\left(m, n=2 n^{\tilde{n}}\right)=\delta\left(m=2, n=2 n^{\tilde{n}}\right)=4>0 .
$$

To sum up, we have: $\delta(m, n)$ is positive for all $2 \leq m \leq n-1,3 \leq n$.

ii. Consideration of $\gamma(m, n)$ :

$$
\frac{\partial \gamma(m, n)}{\partial n}=\delta(m, n)>0 \quad \forall 2 \leq m \leq n-1,3 \leq n .
$$

Therefore $\gamma(m, n)$ has a minimum (in the relevant range $2 \leq m \leq n-1,3 \leq n$ ) at $n=m+1$. We have

$$
\begin{aligned}
& \gamma(m, n+1) \\
& =(2+m)(4+3 m+\sqrt{m}(\sqrt{4+m}-\sqrt{-\sqrt{2} \sqrt{2+m-\underbrace{\sqrt{m} \sqrt{4+m}}_{>-\sqrt{2}}})})>0 .
\end{aligned}
$$

As a consequence, $\gamma(m, n)$ and $\frac{\partial y(m, n)}{\partial n}$ are positive for all $2 \leq m \leq n-1,3 \leq n$. 
Since $\delta(m, n)$ and $\gamma(m, n)$ are positive in the relevant range, we know that $i(m, n)$ has its minimum (given $m$ ) at $n=m+1$. We define

$$
I(m) \equiv i(m, n=m+1) .
$$

(b) Step 2: We will show that $I(m)$ is positive for all $2 \leq m$. We have

$$
I(m)=-1+\frac{\varsigma}{\tau}
$$

with

$$
\tau=16 m(1+m)^{2}(4+m)
$$

and

$$
\begin{aligned}
\varsigma & =\{(2+m)(4+3 m+\sqrt{m}(\sqrt{4+m}-\sqrt{2} \sqrt{2+m-\sqrt{m(4+m)}}))\}^{2} \\
& =\{(2+m)(4(1+m))\}^{2} .
\end{aligned}
$$

The correctness of the last simplification is shown in the following calculation:

$$
\begin{gathered}
4+3 m+\sqrt{m}(\sqrt{4+m}-\sqrt{2} \sqrt{2+m-\sqrt{m(4+m)})}=4(1+m) \\
\Longleftrightarrow \underbrace{\sqrt{m}}_{>0}(-\sqrt{m}+\sqrt{4+m}-\sqrt{2} \sqrt{2+m-\sqrt{m(4+m)}})=0 \\
\Longleftrightarrow \underbrace{\sqrt{4+m}-\sqrt{m}}_{>0}=\underbrace{\sqrt{2} \sqrt{2+m-\sqrt{m(4+m)}}}_{>0} \\
\Longleftrightarrow(4+m)+m-2 \sqrt{m(4+m)}=2(2+m-\sqrt{m(4+m)}),
\end{gathered}
$$

which always holds. We have

$$
\begin{gathered}
I(m)>0 \Longleftrightarrow \varsigma>\tau \Longleftrightarrow \sqrt{\varsigma}>\sqrt{\tau} \Longleftrightarrow \sqrt{\varsigma}-\sqrt{\tau}>0, \\
\sqrt{\tau}=4(1+m) \sqrt{m} \sqrt{4+m}<4(1+m)(2+m) \equiv v
\end{gathered}
$$

and

$$
\sqrt{\varsigma}-v=0 . \quad \forall m \geq 2 .
$$

From the inequality (39) and the conclusion (38) follows $I(m)>0$ for all $m \geq 2$.

To sum up, inequality (36) is fulfilled. 


\subsection{Proof of Proposition 2}

\section{Stage 4}

The firms behave rationally since they maximize profits by choosing their production quantities as described in subsection 5.2.

\section{Stage 3}

The regulator has to maximize social welfare, given every possible combination of investment decisions of the firms. We make a case differentiation:

1. All firms have invested:

The regulator introduces no regulation; there are no emissions.

2. No firm has invested:

The regulator maximizes social welfare by using the tax rate $t^{0}$.

3. $m$ firms have invested $(1 \leq m<n)$ (without the loss of generality the first $m$ firms):

$Q_{N I}=(n-m) q_{n}$ is a strictly decreasing function of $t_{m}$ for $t_{m} \in\left[0, t_{m}^{*}\right]$ :

From the first order condition of the $n$-th firm follows

$$
q_{n}=\frac{1-t_{m}-m q_{1}}{b(n-m+1)} .
$$

$q_{n}$ is a strictly decreasing function of $t_{m}$ if $q_{1}$ is a strictly increasing function of $t_{m}$. We have:

$$
\begin{aligned}
\frac{\partial q_{1}}{\partial t_{m}} & >0 \Longleftarrow \frac{\partial\left(4(m-1)(m-n)(1+n)(t-1) t+(m(t-1)-n t)^{2}\right)}{\partial t_{m}}>0 \\
& \Longleftrightarrow 2(m-n)\left((2-3 m+2 n-2 m n)+(-4+5 m-5 n+4 m n) t_{m}\right) \equiv x\left(n, m, t_{m}\right) .
\end{aligned}
$$

We consider two cases concerning $m$ in turn:

(a) $m \geq 2: \quad t_{m} \leq \frac{1}{3}$

$$
x\left(n, m, t_{m}\right) \geq 2(m-n)\left(\frac{2}{3}+\frac{n}{3}-\frac{4 m}{3}-\frac{2 m n}{3}\right)>0
$$

(b) $m=1: \quad t_{m}=\frac{1}{2}$

$$
\begin{aligned}
x\left(n, m, t_{m}\right) & =2(n-1)\left(\frac{1+n}{2}\right)>0 \\
& \Longrightarrow \frac{\partial q_{1}}{\partial t_{m}}>0 \\
& \Longrightarrow \frac{\partial Q_{N I}}{\partial t_{m}}<0
\end{aligned}
$$


$Q_{N I}$ is zero if $t_{m}$ is $t_{m}^{*}$. There are no emissions then. The non-investing firm makes a profit of zero. Therefore the regulator maximizes social welfare by using the tax rate $t_{m}^{*}$

\section{Stage 2}

The correctness of the proposition is shown if it is a strictly dominant strategy to invest. We consider (without the loss of generality) the first firm. It is a strictly dominant strategy to invest for the first firm if the following three conditions are fulfilled:

1. No other firm invests:

$$
\frac{1}{4 b}-K>\pi_{1}^{0}
$$

2. Some of the other firms invest:

$$
\frac{1}{b(1+m)^{2}}-K>0
$$

3. All other firms invest:

$$
\pi_{1}^{c}-K>0
$$

First we consider condition (40):

$$
\begin{aligned}
\frac{1}{4 b}-K & >\pi_{1}^{0} \Longleftarrow \frac{1}{4 b}-\frac{1}{(n+1)^{2} b}>\frac{\left(1-t^{0}\right)^{2}}{(n+1)^{2} b} \Longleftarrow \frac{1}{4}>\frac{2}{(n+1)^{2}} \\
& \Longleftrightarrow(n+1)^{2}>8 \Longleftarrow n \geq 2
\end{aligned}
$$

Now we consider condition (41):

$$
\frac{1}{b(1+m)^{2}}-K>0 \Longleftarrow \frac{1}{b(1+n)^{2}}>K,
$$

which is fulfilled by assumption.

The condition (42) is fulfilled by the same assumption. 


\section{References}

[1] Breitscheidel, J. and H. Gersbach (2002): Taxes or Subsidies in Self-financing Environmental Mechanisms?, Discussion Paper No 387, University of Heidelberg.

[2] Gersbach, H. (2002): How to get firms to invest: A simple solution to the hold-up problem in regulation, Review of Economic Design, 7, 45-56.

[3] Gilbert, R. J. and Newberry, D. M. (1994): The dynamic efficiency of regulatory constitutions, Rand Journal of Economics, 25(4), 538-554.

[4] Hart, O. (1995): Firms, Contracts, and Financial Structure, Oxford University Press.

[5] Joskow, P. L. (1987): Contract duration and relationship-specific investments: Empirical evidence from coal markets, American Economic Review, 77(1), 168-185.

[6] Jung, C., Krutilla, K. and Boyd, R. (1996): Incentives for advanced pollution abatement technology at the industry level: An evaluation of policy alternatives, Journal of Environmental Economics and Management, 30(1), 95-111.

[7] Klein, B., Crawford, R. G. and Alchian, A. A. (1978): Vertical integration appropriable rents, and the competitive contracting process, Journal of Law and Economics, 21, 297-326.

[8] Laffont, J. J. and Tirole, J. (1996): Pollution permits and environmental innovation, Journal of Public Economics, 62: 127-140.

[9] Levy, B. and Spiller, P. T. (1997): A framework for resolving the regulatory problem, in: Levy and Spiller: Regulations, institutions, and commitment: Comparative studies of telecommunications, New York: Cambridge University Press.

[10] Matsuyama, K. (1990): Perfect equilibrium in a trade liberalization game, American Economic Review, 80: 480-492.

[11] Milliman, S. R. and Prince, R. (1989): Firm incentives to promote technological change in pollution control, Journal of Environmental Economics and Management, 17(3), 247265.

[12] Moore, J. (1992): Implementation, contracts and renegotiation in environments with complete information, in: Laffont, J. J.: Advances in economic theory: Sixth world congress, Cambridge: Cambridge University Press, 182-281.

[13] New York Times, May 27, 1998. 
[14] Requate, T. (1995): Incentives to adopt new technologies under different pollutioncontrol policies, International Tax and Public Finance, 2: 295-317

[15] Requate, T. and Unold, W. (2003): Environmental policy incentives to adopt advanced abatement technology - will the true ranking please stand up?, European Economic Review, 47, 125-146.

[16] Salant, D. J. and Woroch, G. A. (1992): Trigger price regulation, Rand Journal of Economics, 23(1), Spring, 29-51.

[17] Staiger, R. W. and Tabellini, G. (1987): Discretionary trade policy and excessive protection, American Economic Review, 77, 823-837.

[18] Tornell, A. (1991): Time inconsistency of protection programs, Quarterly Journal of Economics, August, 963-974.

[19] Urbiztondo, S. (1994): Investment without regulatory commitment - the case of elastic demand, Journal of Regulatory Economics, 6(1), 87-96.

[20] Varian, H. L. (1994): A solution to the problem of externalities when agents are wellinformed, American Economic Review, 84(5), 1278-1293.

[21] Weimann, J. (1995): Umweltökonomik, Berlin: Springer.

[22] Williamson, O. E. (1983): Credible commitments: Using hostages to support exchange, American Economic Review, 83, 519-540. 